\title{
Implementasi metode Fuzzy Tsukamoto untuk menentukan hasil tes kesehatan pada penerimaan peserta didik baru di Sekolah Menengah Kejuruan
}

\author{
Muqodimah Nur Lestari a, Pio Arfianova Fitrizky Islami ${ }^{b}$, Kirya Mateeke Moses c, Aji Prasetya \\ Wibawa $^{d}$ \\ a,b,c,d Pendidikan Kejuruan, Universitas Negeri Malang, Malang, Indonesia \\ email:amuqodimah11@gmail.com, bpio.arfianova@gmail.com,ckiryamosesm@gmail.com,daji.prasetya.ft@um.ac.id
}

\begin{tabular}{l}
\hline I N F O A R T I K E L \\
\hline Sejarah artikel: \\
Menerima 17 Februari 2017 \\
Revisi 28 Juli 2018 \\
Diterima 28 Juli 2018 \\
Online 28 Juli 2018 \\
\hline Kata kunci: \\
Center Average Defuzzifier \\
Fuzzy Tsukamoto \\
penerimaan peserta didik \\
SMK \\
tes kesehatan \\
\hline Keywords: \\
Center Average Defuzzifier \\
Fuzzy Tsukamoto \\
new student admission \\
medical check up \\
vocational high school \\
\hline Style APA dalam mensitasi \\
artikel ini: \\
Lestari, M. N., Islami, P. A., \\
Moses, K. M., \& Wibawa, A. \\
P. (2018). Implementasi \\
metode Fuzzy Tsukamoto \\
untuk menentukan hasil tes \\
kesehatan pada penerimaan \\
peserta didik baru di \\
Sekolah Menengah \\
Kejuruan. Register: Jurnal \\
Ilmiah Teknologi Sistem \\
Informasi, 4(1), 7-13. \\
\end{tabular}

\begin{abstract}
ABSTRAK
Sekolah Menengah Kejuruan (SMK) hendaknya mampu menciptakan siswa siap kerja, tidak hanya di sekolah saja dilakukan tes kesehatan. Pada saat memasuki dunia kerja, para siswa juga akan dites kesehatan oleh perusahaan untuk memastikan riwayat kesehatan calon tenaga kerja. Dalam hal ini, pihak sekolah tentunya tidak ingin jika para siswa tidak bisa masuk ke perusahaan karena terbentur dengan riwayat kesehatan. Oleh karena itu, pemeriksaan kesehatan merupakan salah satu persyaratan utama dalam menyeleksi calon siswa baru pada SMK. Dalam makalah ini akan dikembangkan sebuah sistem penentuan status kesehatan peserta didik SMK yang terkomputerisasi. Model yang digunakan dalam kajian ini adalah Fuzzy Tsukamoto. Metode Fuzzy Tsukamoto dilakukan yang pertama kali untuk menentukan fungsi keanggotaannya, kemudian menentukan rule, dan nantinya kategori akan diklasterisasi ke masingmasing kelompok sesuai dengan rule yang diterapkan. Metode Tsukamoto yang digunakan adalah metode defuzzikfikasi rata-rata terpusat (Center Average Defuzzifier). Kesimpulan yang didapat dari penelitian ini adalah penggunaan Logika Fuzzy dengan metode Tsukamoto dapat menentukan status kesehatan pada calon siswa SMK.
\end{abstract}

ABSTRACT

Vocational High School should be able to prepare students for ready to work. Medical examination is the last step for recruitment process. It is conducted by the company to ascertain the medical history of the prospective workforce. In this case, the school certainly would not want the students can not get into the company because it collided with a medical history. Therefore, medical examination is one of the main requirements in selecting new students in vocational high school. In this paper, a computerized system for determining the health status of vocational high school student developed. The model used in this study is developed. Fuzzy Tsukamoto determines the membership function, then defines the rule, and the categories will be clustered in to different groups according rule applied. The Tsukamoto which was used here is the Center Average Defuzzifier method. The conclusion obtained from this research is the use of Fuzzy Logic with Tsukamoto method can determine health status in prospective students of vocational high school.

(c) 2018 Register: Jurnal IImiah Teknologi Sistem Informasi. Semua hak cipta dilindungi undang-undang.

\section{Pendahuluan}

Seluruh Sekolah Menengah Kejuruan (SMK) rujukan di Pasuruan sepakat mengadakan tes kesehatan untuk para calon siswanya, karena itu sangat penting untuk mengetahui riwayat kesehatan siswa tersebut. Sebagai lembaga pendidikan yang menyiapkan lulusannya untuk siap kerja, siswa SMK disiapkan untuk memasuki dunia usaha/dunia industri ditinjau dari pengetahuan dan keterampilan 
kerja, mental kerja, sikap kerja, ataupun kesehatan fisik. Jika mempunyai riwayat kesehatan fisik yang tidak baik, maka akan memengaruhi ketika memasuki dunia kerja.

SMK hendaknya mampu menciptakan siswa siap kerja, tidak hanya di sekolah saja dilakukan tes kesehatan. Pada saat memasuki dunia kerja, para siswa juga akan dites kesehatan oleh perusahaan untuk memastikan riwayat kesehatan calon tenaga kerja. Dalam hal ini, pihak sekolah tentunya tidak ingin jika para siswa tidak bisa masuk ke perusahaan karena terbentur dengan riwayat kesehatan. Oleh karena itu, pemeriksaan kesehatan merupakan salah satu persyaratan utama dalam menyeleksi calon siswa baru pada SMK.

Model yang digunakan dalam kajian ini adalah Fuzzy, karena menurut Urbanowicz dan Moore, Fuzzy memiliki keunggulan dalam hal perhitungannya yang tidak kaku (samar), sehingga mampu memperhitungkan kemungkinan tidak pasti (Izzah \& Widyastuti, 2016). Sedangkan metode Fuzzy yang digunakan adalah Tsukamoto, yang mana Fuzzy Tsukamoto memiliki tahapan yang pertama kali adalah menentukan fungsi keanggotaannya, kemudian menentukan rule, dan nantinya kategori akan diklasterisasi ke masing-masing kelompok sesuai dengan rule yang diterapkan. Metode yang digunakan pada model Tsukamoto adalah metode defuzzifikasi rata-rata terpusat atau biasa disebut Center Averaged Defuzzifier (Abdurrahman, 2011).

Arifin, Asfani, dan Handayani (2016) menerapkan metode Fuzzy Tsukamoto untuk menentukan akurasi perhitungan dalam penentuan beasiswa, karena selama ini penetapan penerima beasiswa belum tepat sasaran. Arifin, Asfani, dan Handayani (2016) menetapkan kreteria penentuan penerima beasiswa meliputi tiga hal, yaitu penghasilan orang tua mahasiswa, tanggungan orang tua mahasiswa, dan IPK mahasiswa. Ayuningtiyas, Saptono, dan Hidayat (2007) meneliti tentang penanganan kesehatan balita menggunakan penalaran Fuzzy Mamdani, yang bertujuan untuk mengatasi permasalahan yang dapat ditangani secara mandiri dan lebih akurat, tidak berdasarkan asumsi. Adapun variabel yang diusulkan adalah umur, bobot berdasarkan jenis kelamin, tinggi badan berdasarkan jenis kelamin, dan nilai gizi berdasarkan jenis kelamin. Sedangkan Fidiantoro dan Setiadi (2013) mengusulkan metode Fuzzy dengan kreteria berat badan berdasarkan umur, tinggi badan berdasarkan umur, dan berat badan berdasarkan tinggi badan untuk menentukan status gizi pada balita.

Perbedaan dari ketiga penelitian sebelumnya dengan kajian sekarang adalah dari kriteria yang diciptakan dan sasaran yang dituju dalam penentuan status kesehatan penerimaan peserta didik SMK. Dalam penelitian ini akan dikembangkan sebuah sistem penentuan status kesehatan peserta didik SMK yang terkomputerisasi. Menggunakan metode Fuzzy Logic Tsukamoto, di mana di dalamnya terdapat beberapa tiga tahapan yaitu (Mukminna, Putri, \& Handayani, 2017): (1) Fuzzyfication; (2) Inference engine; dan (3) Defuzzification.

\section{Metode Penelitian}

Pada penelitian ini, metode penelitian untuk membangun sistem diilustrasikan berupa diagram alir atau flowchart ditunjukkan pada Gambar 1. Pada perhitungan Fuzzy Logic terdapat tiga tahapan yang harus dilalui, yaitu: (a) Fuzzyfication; (b) Inference Engine; dan (c) Defuzzification.

\subsection{Fuzzyfication}

Pengumpulan data sebagai input awal dari metode fuzzyfication dilakukan kepada calon siswa SMK di Malang pada periode September 2015. Kemudian dilanjutkan tahapan pertama Fuzzyfication, yaitu dengan melakukan input nilai kebenarannya bersifat pasti (crisp input) dikonversi ke bentuk Fuzzy input, yang berupa nilai linguistik yang semantiknya ditentukan berdasarkan fungsi keanggotaan. Data tersebut berdasarkan standar Body Mass Index (BMI) Indonesia untuk usia remaja (Consultation, 2004). Pada tahapan ini yang menjadi crisp input adalah nilai dari setiap variabel input yang terdiri dari variabel umur, variabel jenis kelamin, variabel tinggi badan dan berat badan. Tabel 1 adalah perancangan himpunan Fuzzy pada sistem pendukung keputusan penentuan status kesehatan calon siswa SMK.

Variabel umur dibagi menjadi 5 himpunan Fuzzy yaitu: Fase 1, fase 2 sampai fase 5. Variabel kondisi berat badan dibagi menjadi 2 variabel, yaitu laki-laki dan perempuan, dan dibagi menjadi 3 himpunan Fuzzy yaitu: Kurus, ideal dan berat. Variabel kondisi tinggi badan dibagi menjadi 2 variabel 
yaitu laki-laki dan perempuan, dan dibagi menjadi 3 himpunan Fuzzy yaitu: Pendek, sedang dan tinggi. Variabel nilai gizi siswa dibagi menjadi 2 variabel yaitu laki-laki, dan perempuan dan dibagi menjadi 5 himpunan Fuzzy yaitu: Buruk, kurang, sedang, baik, dan lebih.

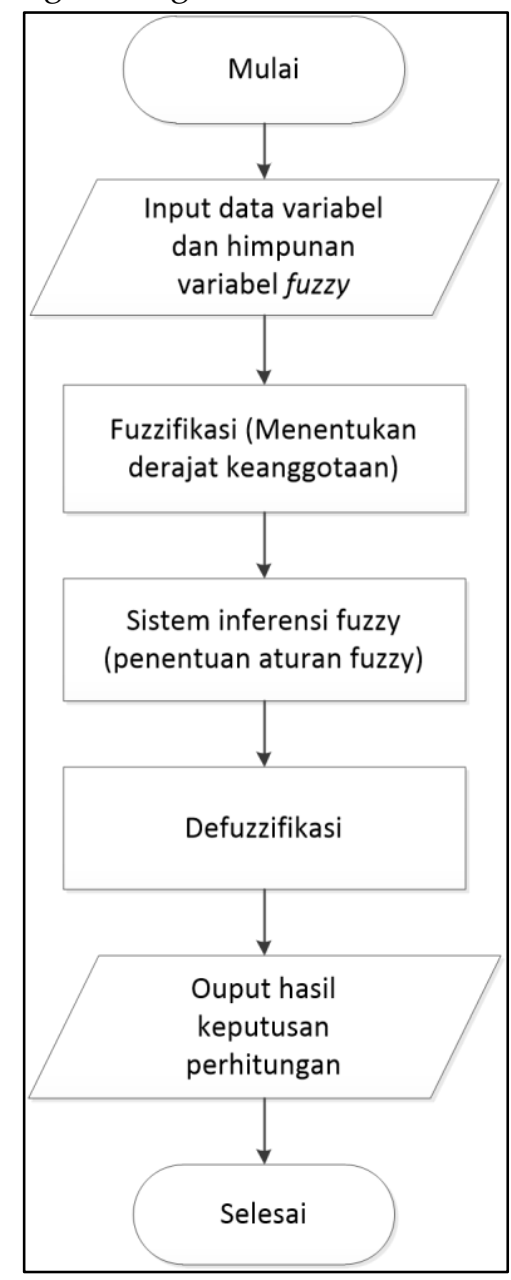

Gambar 1. Flowchart Logika Fuzzy

\subsection{Inference engine}

Inferensi adalah proses penggabungan banyak aturan berdasarkan data yang tersedia. Komponen yang melakukan inferensi dalam sistem pakar disebut mesin inferensi. Dua pendekatan untuk menarik kesimpulan pada IF-THEN rule (aturan jika-maka) (Turban, Aronson, \& Liang, 2007). Inference engine dalam menentukan status kesehatan calon siswa SMK yang didapatkan dengan variabel input umur, berat badan, tinggi badan. Terdapat 45 rule yang didapatkan, namun pada makalah ini hanya ditampilkan sebagian saja yang ditunjukkan pada Tabel 2.

\subsection{Defuzzification}

Pada metode Tsukamoto, implikasi setiap aturan berbentuk implikasi "Sebab-Akibat"/Implikasi "InputOutput", di mana antara anteseden dan konsekuen harus ada hubungannya. Setiap aturan direpresentasikan menggunakan himpunan-himpunan Fuzzy, dengan fungsi keanggotaan yang monoton. Kemudian untuk menentukan hasil tegas (Crisp Solution) digunakan rumus penegasan (defuzifikasi) yang disebut "Metode rata-rata terpusat" atau "Metode defuzifikasi rata-rata terpusat (Center Average Deffuzzyfier) (Setiadji, 2009) yang ditunjukkan pada Persamaan 1. Defuzzifikasi menggunakan model Tsukamoto yaitu mengkonversi himpunan Fuzzy keluaran ke bentuk bilangan crips dengan metode perhitungan rata-rata terbobot (Weighted Average),

Keluaran Crips $=\frac{\sum(\text { Alpha }) x(\text { Konsekuen })}{\sum \text { Konsekuen }}$

di mana alpha adalah derajat keanggotaan parameter keluaran dan konsekuen adalah nilai parameter keluaran. 


\begin{tabular}{|c|c|c|c|}
\hline \multirow[t]{2}{*}{ No } & \multicolumn{3}{|c|}{ Fuzzyfication } \\
\hline & \multirow{5}{*}{ Variabel Umur } & Fase 1 & 130-150 Bulan \\
\hline \multirow{5}{*}{1} & & Fase 2 & 140-160 Bulan \\
\hline & & Fase 3 & 150-170 Bulan \\
\hline & & Fase 4 & 160-180 Bulan \\
\hline & & Fase 5 & >180 Bulan \\
\hline & & Kurus & $41-52 \mathrm{Kg}$ \\
\hline \multirow[t]{3}{*}{2} & \multirow[t]{3}{*}{ Variabel Berat Badan Laki-Laki } & Ideal & $45-65 \mathrm{Kg}$ \\
\hline & & Berat & $>61 \mathrm{Kg}$ \\
\hline & & Kurus & $40-51 \mathrm{Kg}$ \\
\hline \multirow[t]{3}{*}{3} & \multirow{3}{*}{ Variabel Berat Badan Perempuan } & Ideal & $44-64 \mathrm{Kg}$ \\
\hline & & Berat & $>61 \mathrm{Kg}$ \\
\hline & & Pendek & $141-156 \mathrm{~cm}$ \\
\hline \multirow[t]{3}{*}{4} & \multirow[t]{3}{*}{ Variabel Tinggi Badan Laki-Laki } & Sedang & $150-165 \mathrm{~cm}$ \\
\hline & & Tinggi & $>160 \mathrm{~cm}$ \\
\hline & & Pendek & $140-155 \mathrm{~cm}$ \\
\hline \multirow[t]{4}{*}{5} & \multirow{3}{*}{ Variabel Tinggi Badan Perempuan } & Sedang & $149-164 \mathrm{~cm}$ \\
\hline & & Tinggi & $>159 \mathrm{~cm}$ \\
\hline & & Buruk & $0-44$ \\
\hline & & Kurang & $44-50$ \\
\hline \multirow[t]{5}{*}{6} & \multirow[t]{4}{*}{ Variabel Nilai Gizi Siswa Laki-Laki } & Sedang & $50-60$ \\
\hline & & Baik & $60-70$ \\
\hline & & Lebih & $70-120$ \\
\hline & & Buruk & $0-43$ \\
\hline & \multirow{4}{*}{$\begin{array}{l}\text { Variabel Nilai Gizi Siswa } \\
\text { Perempuan }\end{array}$} & Kurang & $43-49$ \\
\hline \multirow[t]{3}{*}{7} & & Sedang & $49-59$ \\
\hline & & Baik & $59-79$ \\
\hline & & Lebih & $79-110$ \\
\hline
\end{tabular}

Tabel 2. Aturan - aturan Fuzzy

\begin{tabular}{lllll}
\hline No & IF & \multicolumn{1}{c}{ FASE and BB and TB } & THEN & \multicolumn{1}{c}{ Status } \\
\hline 1 & IF & FASE 1 and RINGAN and RENDAH & THEN & Baik \\
2 & IF & FASE 1 and RINGAN and SEDANG & THEN & Baik \\
3 & IF & FASE 1 and RINGAN and TINGGI & THEN & Sedang \\
4 & IF & FASE 1 and SEDANG and RENDAH & THEN & Lebih \\
5 & IF & FASE 1 and SEDANG and SEDANG & THEN & Lebih \\
6 & IF & FASE 1 and SEDANG and TINGGI & THEN & Lebih \\
7 & IF & FASE 1 and BERAT and RENDAH & THEN & Lebih \\
8 & IF & FASE 1 and BERAT and SEDANG & THEN & Lebih \\
9 & IF & FASE 1 and BERAT and TINGGI & THEN & Lebih \\
& & & & \\
38 & IF & FASE 5 and RINGAN and SEDANG & THEN & Buruk \\
39 & IF & FASE 5 and RINGAN and TINGGI & THEN & Buruk \\
40 & IF & FASE 5 and SEDANG and RENDAH & THEN & Kurang \\
41 & IF & FASE 5 and SEDANG and SEDANG & THEN & Kurang \\
42 & IF & FASE 5 and SEDANG and TINGGI & THEN & Kurang \\
43 & IF & FASE 5 and BERAT and RENDAH & THEN & Lebih \\
44 & IF & FASE 5 and BERAT and SEDANG & THEN & Lebih \\
45 & IF & FASE 5 and BERAT and TINGGI & THEN & Baik \\
\hline
\end{tabular}




\section{Hasil dan Pembahasan}

Tabel 3. Pengolahan Data Pengukuran

\begin{tabular}{|c|c|c|c|c|c|c|c|}
\hline No & $\begin{array}{c}\text { Jenis } \\
\text { Kelamin }\end{array}$ & $\begin{array}{c}\text { Umur } \\
\text { (bulan) }\end{array}$ & $\begin{array}{l}\mathrm{TB} \\
(\mathrm{cm})\end{array}$ & $\begin{array}{l}\text { BB } \\
(\mathrm{kg})\end{array}$ & $\begin{array}{c}\text { Status Kesehatan } \\
\text { (Sebutan Fuzzy) }\end{array}$ & $\begin{array}{c}\text { Penilaian } \\
\text { Pakar }\end{array}$ & Hasil \\
\hline 1 & $\mathrm{~L}$ & 145 & 152 & 50 & Baik & Baik & Sama \\
\hline 2 & $P$ & 185 & 168 & 60 & Sedang & Sedang & Sama \\
\hline 3 & $\mathrm{~L}$ & 195 & 177 & 55 & Sedang & Sedang & Sama \\
\hline 4 & $\mathrm{~L}$ & 188 & 170 & 65 & Sedang & Sedang & Sama \\
\hline 5 & $\mathrm{P}$ & 148 & 155 & 58 & Baik & Baik & Sama \\
\hline 6 & $\mathrm{P}$ & 150 & 160 & 55 & Sedang & Sedang & Sama \\
\hline 7 & $\mathrm{~L}$ & 158 & 153 & 45 & Sedang & Sedang & Sama \\
\hline 8 & $\mathrm{~L}$ & 185 & 168 & 55 & Sedang & Sedang & Sama \\
\hline 9 & $P$ & 190 & 165 & 60 & Sedang & Sedang & Sama \\
\hline 10 & $P$ & 160 & 165 & 55 & Sedang & Sedang & Sama \\
\hline 11 & $\mathrm{P}$ & 150 & 155 & 45 & Baik & Baik & Sama \\
\hline 12 & $\mathrm{~L}$ & 145 & 165 & 63 & Sedang & Sedang & Sama \\
\hline 13 & $\mathrm{P}$ & 167 & 160 & 58 & Baik & Baik & Sama \\
\hline 14 & $\mathrm{P}$ & 185 & 177 & 55 & Sedang & Sedang & Sama \\
\hline 15 & $\mathrm{~L}$ & 167 & 141 & 40 & Kurang & Kurang & Sama \\
\hline 16 & $\mathrm{~L}$ & 187 & 168 & 58 & Baik & Baik & Sama \\
\hline 17 & $\mathrm{~L}$ & 158 & 160 & 55 & Kurang & Kurang & Sama \\
\hline 18 & $\mathrm{~L}$ & 161 & 170 & 60 & Baik & Baik & Sama \\
\hline 19 & $\mathrm{~L}$ & 172 & 158 & 66 & Sedang & Sedang & Sama \\
\hline 20 & $\mathrm{~L}$ & 164 & 170 & 55 & Baik & Baik & Sama \\
\hline 21 & $\mathrm{~L}$ & 170 & 166 & 56 & Kurang & Kurang & Sama \\
\hline 22 & $\mathrm{~L}$ & 158 & 156 & 43 & Baik & Baik & Sama \\
\hline 23 & $\mathrm{~L}$ & 153 & 158 & 56 & Kurang & Kurang & Sama \\
\hline 24 & $\mathrm{~L}$ & 160 & 177 & 58 & Baik & Baik & Sama \\
\hline 25 & $\mathrm{~L}$ & 156 & 168 & 57 & Kurang & Kurang & Sama \\
\hline 26 & $\mathrm{~L}$ & 172 & 166 & 45 & Sedang & Sedang & Sama \\
\hline 27 & $\mathrm{~L}$ & 189 & 158 & 48 & Sedang & Sedang & Sama \\
\hline 28 & $\mathrm{~L}$ & 156 & 170 & 60 & Baik & Baik & Sama \\
\hline 29 & $\mathrm{~L}$ & 185 & 160 & 55 & Sedang & Sedang & Sama \\
\hline 30 & $\mathrm{~L}$ & 167 & 158 & 60 & Baik & Baik & Sama \\
\hline 31 & $\mathrm{~L}$ & 178 & 160 & 61 & Sedang & Sedang & Sama \\
\hline 32 & $\mathrm{P}$ & 185 & 167 & 66 & Sedang & Sedang & Sama \\
\hline 33 & $\mathrm{P}$ & 180 & 159 & 45 & Kurang & Kurang & Sama \\
\hline 34 & $\mathrm{~L}$ & 152 & 165 & 56 & Baik & Baik & Sama \\
\hline 35 & $\mathrm{P}$ & 190 & 156 & 60 & Sedang & Sedang & Sama \\
\hline 36 & $\mathrm{~L}$ & 168 & 170 & 45 & Sedang & Sedang & Sama \\
\hline 37 & $\mathrm{~L}$ & 148 & 165 & 52 & Sedang & Sedang & Sama \\
\hline 38 & $\mathrm{P}$ & 178 & 158 & 60 & Baik & Baik & Sama \\
\hline 39 & $\mathrm{P}$ & 182 & 157 & 58 & Sedang & Sedang & Sama \\
\hline 40 & $\mathrm{P}$ & 165 & 159 & 60 & Baik & Baik & Sama \\
\hline 41 & $\mathrm{P}$ & 170 & 154 & 75 & Sedang & Sedang & Sama \\
\hline 42 & $P$ & 180 & 159 & 46 & Kurang & Kurang & Sama \\
\hline 43 & $\mathrm{P}$ & 170 & 160 & 55 & Sedang & Sedang & Sama \\
\hline 44 & $\mathrm{P}$ & 185 & 160 & 60 & Baik & Baik & Sama \\
\hline 45 & $\mathrm{P}$ & 190 & 158 & 60 & Baik & Baik & Sama \\
\hline 46 & $P$ & 183 & 162 & 55 & Baik & Baik & Sama \\
\hline 47 & $\mathrm{P}$ & 183 & 153 & 45 & Sedang & Sedang & Sama \\
\hline 48 & $\mathrm{P}$ & 190 & 159 & 60 & Sedang & Sedang & Sama \\
\hline 49 & $P$ & 188 & 155 & 60 & Sedang & Sedang & Sama \\
\hline 50 & $\mathrm{P}$ & 185 & 162 & 58 & Sedang & Sedang & Sama \\
\hline
\end{tabular}

Pada penelitian ini dilakukan uji coba kepada 50 siswa, setiap tes dianalisis menggunakan Fuzzy Tsukamoto, untuk menghitung penentuan status kesehatan siswa SMK, yang terdapat empat variabel input, diantaranya: Umur siswa, jenis kelamin, tinggi badan dan berat badan. Hasil pengujian Fuzzy Tsukamoto dibandingkan dengan penilaian pakar, hasil pengujian dapat dilihat pada Tabel 3. Tabel 3 
menampilkan sebagian uji coba tes penentuan status kesehatan siswa, proses input tersebut disesuaikan dengan data siswa.

Berdasarkan hasil pengujian yang disajkan pada Tabel 3, maka dapat dikatakan untuk peserta tes kesehatan dengan kategori seperti yang ditampilkan pada Tabel 4. Berdasarkan analisis data pada Tabel 4, maka dapat dikatakan bahwa tes kesehatan untuk calon siswa SMK adalah kategori kurang dengan jenis kelamin laki-laki dengan jumlah 5 siswa dari 50 siswa, sedangkan kategori kurang dengan jenis kelamin perempuan dengan jumlah 2 siswa dari 50 siswa. Kategori sedang dengan jenis kelamin laki-laki dengan jumlah 12 siswa dari 50 siswa, sedangkan kategori sedang dengan jenis kelamin perempuan dengan jumlah 14 siswa dari 50 siswa. Kategori baik dengan jenis kelamin laki-laki dengan jumlah 9 siswa dari 50 siswa, sedangkan kategori baik dengan jenis kelamin perempuan dengan jumlah 8 siswa dari 50 siswa. Membandingkan hasil penilaian sistem pakar dengan hasil penilaian menggunakan metode Fuzzy Tsukamoto yang telah diuji ditunjukkan pada Tabel 3 menunjukkan hasil yang sama.

Tabel 4. Hasil Pengolahan data

\begin{tabular}{lccc}
\hline \multicolumn{1}{c}{ Jenis Kelamin } & Kurang & Sedang & Baik \\
\hline Laki-laki & 5 & 12 & 9 \\
Perempuan & 2 & 14 & 8 \\
\hline
\end{tabular}

Dengan hasil pengolahan data pengukuran, maka diperoleh status kesehatan siswa dengan kategori sedang jenis kelamin laki-laki sebesar 12 dan jenis kelamin perempuan 14, menunjukkan kepada klasifikasi rata-rata peserta tes adalah kategori sedang. Pada penelitian ini, hasil uji coba menggunakan metode Fuzzy Tsukamoto memiliki nilai yang serupa sesuai dengan hasil penilaian pakar. Selanjutnya dapat dilakukan analisis lebih mendalam terkait dengan tingkat keberhasilan metode ini. Pada penelitian selanjutnya juga dapat dilakukan perbandingan antara penggunakan metode Fuzzy dengan metode konvensional.

\section{Kesimpulan}

Penggunaan logika Fuzzy menggunakan metode Tsukamoto dapat menentukan status kesehatan pada calon siswa SMK dengan menggunakan Fuzzy Logic. Terdapat empat variabel input dan satu variabel output, diantaranya variabel input; umur siswa, jenis kelamin, tinggi siswa, dan berat badan siswa. Sedangkan variabel output adalah status kesehatan siswa. Penelitian ini diharapkan membantu SMK dalam tes kesehatan penerimaan peserta didik baru, sehingga dapat melakukan analisis terhadap penilaian status kesehatan calon peserta didik yang lebih cepat dan akurat. Meskipun untuk kehandalan metode ini masih perlu dilakukan penelitian selanjutnya terkait dengan akurasi metode fuzzy dibandingkan metode konvensional.

\section{Referensi}

Abdurrahman, G. (2011). Penerapan Metode Tsukamoto (Logika Fuzzy) dalam Sistem Pendukung Keputusan untuk menentukan jumlah produksi barang berdasarkan data persediaan dan jumlah permintaan. Yogyakarta: Universitas Negeri Yogyakarta.

Arifin, M., Asfani, K., \& Handayani, A. N. (2016). Akurasi perhitungan dalam penentuan beasiswa dengan metode Fuzzy Tsukamoto berbasis web. Jurnal Maklumatika, 3(1), 10-21.

Ayuningtiyas, I. K., Saptono, F., \& Hidayat, T. (2007). Sistem Pendukung Keputusan penanganan kesehatan balita menggunakan penalaran Fuzzy Mamdani. Seminar Nasional Aplikasi Teknologi Informasi (SNATI) (pp. L65-L71). Yogyakarta: Universitas Islam Indonesia.

Consultation, W. E. (2004). Appropriate body-mass index for Asian populations and its implications for policy and intervention strategies. THE LANCET, 363, 157-163.

Fidiantoro, N., \& Setiadi, T. (2013). Model penentuan status gizi balita di Puskesmas. Jurnal Sarjana Teknik Informatika, 1(1), 367-373.

Izzah, A., \& Widyastuti, R. (2016). Prediksi Kelulusan Mata Kuliah Menggunakan Hybrid Fuzzy Inference System. Register: Jurnal Ilmiah Teknologi Sistem Informasi, 2(2), 60-67. doi:http://dx.doi.org/10.26594/register.v2i2.548 
Mukminna, H., Putri, D. M., \& Handayani, A. N. (2017). Simulasi kinerja siswa dengan metode Fuzzy Inference Sugeno menggunakan aplikasi Matlab. Jurnal Ilmiah Teknologi dan Informasi ASIA (JITIKA), 11(1), 71-78.

Setiadji, S. (2009). Himpunan \& Logika Samar serta aplikasinya. Yogyakarta: Graha Ilmu.

Turban, E., Aronson, J. E., \& Liang, T.-P. (2007). Decission Support Systems and Intelligent Systems. New Delhi: Prentice-Hall. 